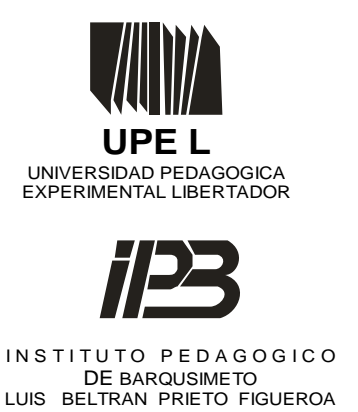

DE BARQUSIMETO
LUIS BELTRAN PRIETO FIGUEROA

\title{
REVISTA
}

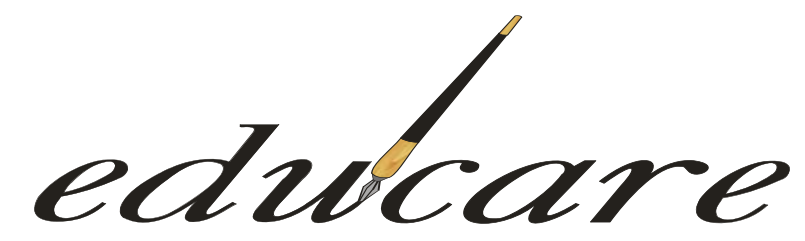

Órgano Divulgativo de la Subdirección de Investigación y Postgrado del Instituto Pedagógico de Barquisimeto “Luis Beltrán Prieto Figueroa"

BARQUISIMETO - EDO. LARA - VENEZUELA

NUEVA ETAPA

FORMATO ELECTRÒNICO

DEPOSITO LEGAL: ppi201002LA3674

ISSN: $2244-7296$

Volumen $18 \mathbf{N}^{\circ} 2$

Mayo - Agosto 2014

TEORÍA DE LA VIOLENCIA ESCOLAR:

VISIÓN DE LOS ACTORES DE UNA ESCUELA VENEZOLANA

THEORY OF SCHOOL VIOLENCE: PERSPECTIVE OF ACTORS FROM A VENEZLELAN SCHOOL

Freddy Mayora*
Matilde Castillo**

* Universidad Nacional Experimental Simón Rodríguez Núcleo de Educación Avanzada Caracas

** Instituto Pedagógico de Caracas. Universidad Nacional Experimental Libertador 
Teoría de la violencia escolar: visión de los actores de una escuela venezolana.

Freddy Mayora, Matilde Castillo ( Pp. 52-72)

\section{TEORÍA DE LA VIOLENCIA ESCOLAR: VISIÓN DE LOS ACTORES DE UNA ESCUELA VENEZOLANA}

\section{THEORY OF SCHOOL VIOLENCE: PERSPECTIVE OF ACTORS FROM A VENEZUELAN SCHOOL}

\begin{tabular}{|c|c|}
\hline TRABAJO DE INVESTIGACIÓN & $\begin{array}{l}\text { Freddy Mayora. } \\
\text { Matilde Castillo** }\end{array}$ \\
\hline Recibido: $12 / 03 / 2014$ & Aceptado: $22 / 07 / 2014$ \\
\hline RESUMEN & ABSTRACT \\
\hline $\begin{array}{l}\text { La investigación tuvo como propósito } \\
\text { construir una teoría sustantiva de la } \\
\text { violencia escolar desde la visión de sus } \\
\text { miembros. El estudio se desarrolló en una } \\
\text { Unidad Educativa Nacional de Caracas. El } \\
\text { diseño se fundamentó en el paradigma } \\
\text { interpretativo fenomenológico con enfoque } \\
\text { cualitativo. Los hallazgos indican que la } \\
\text { comunidad escolar está afectada por un } \\
\text { cúmulo de déficits, vulnerabilidad social e } \\
\text { indefensión. Se formuló la Teoría de } \\
\text { Violencia Sistémica, pensada como una } \\
\text { fuerza ejercida desde niveles en los cuales } \\
\text { el individuo no tiene poder de decisión. Se } \\
\text { recomienda que las acciones deban dirigirse } \\
\text { a la creación de núcleos integrales de } \\
\text { educación en cuales funcionen servicios de } \\
\text { promoción y prevención de salud en los } \\
\text { jóvenes; impulsar programas nacionales, } \\
\text { sustentado en el pensamiento complejo, de } \\
\text { convivencia escolar, acompañados de } \\
\text { acciones que conlleven la mitigación del } \\
\text { riesgo y la vulnerabilidad. A otras } \\
\text { instancias, abordar la escuela como } \\
\text { laboratorio social donde se busque } \\
\text { profundizar el fenómeno estudiado. } \\
\text { Descriptores: teoría sustantiva, violencia } \\
\text { escolar, violencia sistémica. }\end{array}$ & $\begin{array}{l}\text { The aim was to build a substantive theory of } \\
\text { school violence from the view of school } \\
\text { members. The study was developed in a } \\
\text { national educative institution in Caracas. } \\
\text { The design was based on the interpretative } \\
\text { phenomenological paradigm with a } \\
\text { qualitative approach. Findings indicate that } \\
\text { school community is affected for a set of } \\
\text { deficits, social vulnerability and } \\
\text { helplessness. The Systemic Violence } \\
\text { Theory was presented; it was seen as an } \\
\text { exerted force from levels in which the } \\
\text { individual has not power decision. It is } \\
\text { recommended that actions must be } \\
\text { addressed to the creation of integral nuclei } \\
\text { of education in which health promotion and } \\
\text { prevention services for the youths really } \\
\text { work; enhance national programs of school } \\
\text { conviviality based on complex thinking } \\
\text { along with actions leading to risk and } \\
\text { vulnerability alleviation. }\end{array}$ \\
\hline
\end{tabular}

*Profesor asociado de la Universidad Nacional Experimental Simón Rodríguez Núcleo de Educación Avanzada Caracas. Doctor en Educación, Maestría en Educación Ambiental. Correo: fmayora46@gmail.com ** Profesora asociada, contratada, del Instituto Pedagógico de Caracas. Universidad Nacional Experimental Libertador, Doctorado de Educación Ambiental. Maestría en Educación Ambiental. Correo: matie153@gmail.com 


\section{INTRODUCCIÓN}

El ser humano interactúa con el ambiente donde se desenvuelve, esta dinámica está enriquecida por el bagaje social y por las instituciones que constituyen su espacio vital y contribuyen a delinear su personalidad. Una de las instituciones sociales que ejerce mayor influencia en la formación del ser humano es la escuela la cual se caracteriza por una amplia variedad de escenarios complejos articulados entre si, que deben ser considerados al momento de comprender los procesos entre las personas que allí conviven.

En este orden de ideas, Ross (1999) plantea que los sistemas educativos son productos de las sociedades a las que sirven y como tales se convierten en los recipientes donde se desarrollan las nuevas generaciones para hacer de ellas réplicas de sus predecesores. Lo bueno y lo malo de nuestra cultura se favorece y se realza a lo largo de los años de formación de cada uno de los alumnos. Muchas consecuencias positivas han sido el resultado de la escolarización obligatoria, logrando con ello que las personas alcancen metas individuales al tiempo que se convierten en ciudadanos adaptados socialmente.

En este sentido, la Ley Orgánica de Educación (LOE, 2009) en su artículo $4^{\circ}$ considera:

La educación como derecho humano en condiciones históricamente determinadas, constituye el eje central en la creación, transmisión y reproducción de las diversas manifestaciones y valores culturales, invenciones, expresiones, representaciones y características propias para apreciar, asumir y transformar la realidad...

Empero, es de suponer que los sistemas educativos no hayan tenido el mismo efecto en todos quienes ingresan en él. Hay estudiantes que no se benefician por igual de la educación pública, muchos de ellos no logran alcanzar las metas propuestas, otros abandonan ( $\mathrm{o}$ en algunas oportunidades el sistema los excluye), otros pocos expresan su marginación y frustración mediante actos de violencia. Cuando esto sucede el sistema escolar centra su atención en quienes contravienen las normas, más que en las razones de los arranques de violencia. Todo esto, según Ross (ob. cit), es lo que se hallamado violencia educativa del sistema. 
Las relaciones personales entre quienes hacen vida escolar conllevan cierto grado de agresividad y una expresión violenta de las emociones. Además, las implicaciones que las relaciones sociales en el contexto escolar tienen para la adaptación del niño son tan importantes como las que se derivan del ambiente familiar. Por eso, las conductas agresivas probablemente no sucedan en uno solo de esos contextos ni todas se puedan identificar o suprimir. En síntesis, el estudio de la violencia en la escuela incluye componentes que son propios de los sistemas, no sólo escolar sino el familiar y social.

La escuela objeto de estudio, está rodeada de algunos factores ambientales propios de zonas periurbanas, que se caracterizan por situaciones socio-económicas determinadas por déficits económicos y de servicios. La escuela está rodeada de viviendas multifamiliares, construcciones de casas que han venido proliferando de manera anárquica a través del tiempo, espacios donde habitan familias con diferentes estructuras y características sociales que denotan pérdida de algunos valores morales que afectan la convivencia.

En las zonas aledañas a la escuela son frecuentes los hechos de suma violencia por "ajustes de cuentas", tráfico de drogas, el eco de disparos en diferentes horas del día y la noche, entre otros. Este estado de tensión permanente, de miedo, pudiera afectar de manera directa a los niños, niñas y adolescentes, maestros y profesores, obreros, personal administrativo, en fin, a todos los miembros de la comunidad educativa, incluyendo a los padres y representantes.

En frecuentes conversaciones con el personal directivo de la institución se detectó que las relaciones dentro de la escuela han derivado en una serie de enfrentamientos en torno a conflictos de poca importancia que degeneran en un clima de disgusto y desagrado para todos. Evidencia de esto son las pugnas, que en algunas oportunidades se convierten en agresiones físicas, por parte de estudiantes que allanan sus diferencias de esa forma; otros casos, no tan evidentes son las órdenes de agredir, por terceras personas, a los compañeros de clase con quienes se tiene alguna desavenencia.

Otros aspectos importantes que se han observado en esta institución es la carencia de normas explícitas, tal circunstancia produce una sensación de anarquía al momento de sancionar las faltas, dependiendo del estado de ánimo del docente u otra autoridad escolar el castigo es más o menos fuerte; en la mayoría de las oportunidades la toma de 
decisiones importantes no es consensuada lo cual incide en desacuerdos y situaciones conflictivas; muchos docentes asumen actitudes contradictorias, luego de aplicada una sanción y dejar registrada en los diarios de clase su actuación opinan que probablemente no estaban seguros de la persona a quien se le atribuyó la falta, o si en realidad ésta última era motivo de castigo.

Se pudo evidenciar que el docente en su actividad carece de planificación, manejo de estrategias de enseñanza y resolución de conflictos. La situación descrita conforma un núcleo del cual se derivan infinidades de situaciones conflictivas, consecuencia de esto son los momentos de desorden y falta de atención. También se observó que algunos educadores empleaban un lenguaje que denota poco cuidado del léxico y la sindéresis que debe ser empleada por un profesional de la pedagogía.

Este conjunto de vivencias, asociadas a la necesidad de tener una mejor comprensión del fenómeno de la violencia en las escuelas venezolanas orientaron la presente investigación, con la finalidad de construir una teoría sustantiva que contribuya a proyectar respuestas para enfrentarla apropiadamente.

Vista la complejidad de este micromundo social se consideró necesario indagar acerca de: ¿Cuál es la teoría sustantiva que subyace en las manifestaciones de violencia que ocurren en una institución educativa venezolana a partir de los hechos de la vida cotidiana?

\section{METODOLOGÍA}

El paradigma que sustentó esta investigación fue el interpretativo fenomenológico con enfoque cualitativo. Este enfoque intenta penetrar con un carácter riguroso y sistemático en los fenómenos de la vida cotidiana, explorarlos, analizarlos para lo cual es imprescindible descubrir las actividades diarias, los motivos y significados, así como las acciones y reacciones del actor individual en el contexto de su vida diaria (Pérez, 2000).

En este estudio se interpretaron los significados de los hechos como resultante de una dialéctica entre los valores, creencias e intereses de los actores y la realidad de la escuela estudiada, sin perder de vista la singularidad y el contexto. Se hizo énfasis en la descripción y comprensión de lo único y particular del sujeto más que lo generalizable. 
Actores sociales:

Los actores sociales estuvieron conformados por estudiantes y docentes de la comunidad educativa. Constituyen una unidad seleccionada intencionalmente, utilizando algunos criterios que garantizaron el proceso de la investigación: (a) disposición voluntaria para aportar la información solicitada, (b) consentimiento para realizar las entrevistas y observaciones puntuales tanto en el aula como fuera de ella y (c) posibilidad de encuentro para la realización de la entrevista.

\section{Técnicas e instrumentos:}

La observación permitió registrar sistemáticamente la información derivada de hechos o acontecimientos relevantes que ocurrieron en la escuela. El producto de esta actividad se registró en un diario de campo, en éste se asentó el día y la hora, el docente observado y de los estudiante protagonistas de las acciones más relevantes.

Las entrevistas con preguntas abiertas, realizadas a docentes y estudiantes de manera espontánea sin límite de tiempo, aportaron valiosa información acerca de la violencia escolar como problema de investigación. Como instrumento de registro se utilizaron cintas magnetofónicas (4 cassettes de 60 min cada uno).

Con la información recopilada en las cintas magnetofónicas y el diario de campo se construyeron los protocolos, en ellos las páginas y líneas de las transcripciones están identificadas con las coordenadas que ayudaron a ubicar la información de cada uno de los casos relatados. Por ejemplo, (006, 0242-0247) significa que la cita se corresponde con la página N006 y los números 0242-0247 las líneas correspondientes.

\section{Procedimiento de la Investigación:}

Esta investigación se sistematizó en III momentos: (a) el primer momento, Indagación de la Realidad, se realizó en dos fases, en la primera se efectuaron entrevistas al personal administrativo de la Unidad Psicoeducativa (UPE), a los docentes de educación primaria y a los profesores que ejecutan otras funciones en diferentes ambientes; en la segunda fase se realizaron observaciones en las aulas de educación media y otros espacios de la escuela, como el patio utilizado para el recreo de los niños y adolescentes y la seccional; también entrevistamos algunos estudiantes; (b) en el 
segundo momento, se transcribió el producto de las observaciones y entrevistas, para lo cual se elaboraron los correspondientes protocolos, y luego proceder a la categorización de la información; (c) el momento tercero consistió en la construcción teórica a partir de los resultados de la investigación.

\section{Análisis e Interpretación de los Hallazgos de la Investigación Entrevistas al personal de la Unidad Psicoeducativa (UPE)}

\section{Situaciones reportadas por la Psicopedagoga}

A manera de ejemplo se reportan algunos resultados de las entrevistas al personal que compone esta Unidad. Al preguntarle a la psicopedagoga por los niños y niñas que presentan mayores problemas empezó hablando de José 1:

...un niño de siete años, la madre murió en un parto, no se ha podido ubicar al padre. La abuela vino no hace mucho, pero es una señora muy mayor. Este niño tiene un disparo en un hombro, vivía con sus, hermanos que son bastantes, parece que estaban buscando al tío y él recibió el disparo (006; 0242-0247).

Lo primero que llama la atención es la complejidad de la situación, en un solo individuo recae el ser huérfano, abandonado por el padre, vivir en un ámbito social de violencia y agresión que compromete su vida presente y futura.

Un niño huérfano es aquel que no ha cumplido los dieciocho años y ha perdido a uno o ambos padres. En este caso, la madre. La carencia materna es la mayor pérdida, puesto que ella representa la alimentación y el cuidado en los primeros días de nacido, hecho crucial para la supervivencia; en esta relación el hijo identifica a la progenitora por los olores, su voz o sonidos que emite, esto es gracias al contacto íntimo del acto de ser amamantado. El ser humano forma un todo con la progenitora, es quien lo cuida, lo carga, con expresiones de dulzura y los cuidados oportunos y asiduos que llegan a satisfacer hasta la mínima necesidad del niño, ella le infunde el sentido de seguridad interior que constituye el mejor fundamento de una personalidad en ciernes. 


\section{Los estudiantes vistos por la Orientadora}

En la conversación surgieron otros casos que llamaron la atención del entrevistador, al preguntar por problemas presentados por otros estudiantes la respuesta fue la siguiente:

Sí, es el caso de la venta de drogas. La abuela vino buscando ayuda y nosotros le dijimos que no podíamos hacer nada, que había que ir a la LOPNNA. Porque en la casa de esos niños se vende drogas. El papá pone a los niños a despachar la mercancía cuando tiene que salir. Los niños son una hembra que está en $4^{\circ} y$ dos varones que están en $6^{\circ}$, porque el que está en $7^{\circ}$ lo retiraron en estos dias. Viven en Las Casitas (15, 639-647).

La problemática relacionada con el tráfico y consumo de sustancias ilegales es sumamente compleja, tal como se plantea en el caso observado en la Institución escolar, habría que analizar desde diversas perspectivas qué impulsa a un padre a involucrar en una actividad tan riesgosa a sus hijos menores de edad (entre 9 y 12 años aproximadamente, según lo informado por la trabajadora social). La sola explicación de las carencias económicas, o la aparente facilidad de obtención de cantidades considerables de dinero no son suficientes, debe existir una distorsión de los valores aceptados como válidos por la sociedad, del concepto del Bien y el Mal.

\section{Experiencias narradas por la Trabajadora Social}

La otra persona que colabora en el equipo de la Unidad de Psicopedagogía es la trabajadora social quien tiene información derivada de las visitas realizadas al hogar donde habitan algunos estudiantes. Esta profesional afirma que algunas veces no hay con quien entrevistarse, debido a que los hogares se encuentran sin la presencia de un adulto y las áreas son peligrosas; corre riesgos de ser atracada y no se atreve a acudir a estos domicilios. Como resultado de un caso de suicidio frustrado, la protagonista fue una adolescente, la trabajadora social narró su versión:

Esta niña desde cuarto grado comenzó a presentar problemas de conducta. Nosotros llamábamos al representante, se hablaba con la mamá. Ella vive con su mamá nada más y sus dos hermanitos. La mamá siempre ha sido una mujer conflictiva, aparte de lo económico. Ella y el hermano mayor son hijos de un señor que está fuera de Venezuela, el menor es de otro padre. La muchacha tuvo amoríos con un niño, eso trajo problemas con el profesor ese año, porque el niño estaba enfrascado con esa novia que 
llegó a romper un vidrio para él cortarse, porque la niña no lo quería. (13, 572-582).

De lo expresado por la profesional se deduce que especula acerca de los motivos que pudieron haber provocado el comportamiento de la alumna, la UPE no tiene una versión desde el punto de vista médico o psicológico que permita esclarecer las verdaderas causas. Además de estas crisis personales los alumnos deben enfrentar otras en la escuela, derivadas del comportamiento de contados docentes, tal es el caso que describió la trabajadora social:

Otro caso en el que no me quiero involucrar, es el caso del maltrato de la profesora de educación física, eso no es de ahora. La que trabaja con los varones los insulta, tú sabes. Fíjate que un caso de dos niños damnificados, están con su abuelita porque la mitad de la casa donde viven se vino abajo. Ese día no pudieron traer los uniformes y ella sin preguntarles los devolvió después de darles tremendo regaño. Ella no los escuchó. Les grita en el patio, les dice groserías porque eso yo lo he visto. $Y$ porque ya tuvimos un encontronazo bien feo por lo mismo (016, 674-679).

Los vejámenes sufridos por los estudiantes en la escuela están prohibidos por la ley que resguarda sus derechos, Ley Orgánica de Protección del Niño, Niña y el Adolescente (LOPNNA, 1998), sin embargo, los insultos, gritos, regaños y malas palabras no son de fácil comprobación, por tanto, es muy frecuente que los docentes abusen de la autoridad para ejercer este tipo de comportamiento. En el cuadro 1 se presenta un resumen de las situaciones reportadas por el personal de la UPE.

Cuadro 1.

Situaciones reportadas por el personal de la Unidad Psicoeducativa

\begin{tabular}{c|l}
\hline PERSONAL & \multicolumn{1}{c}{ SITUACIONES REPORTADAS } \\
\hline Psicopedagoga & $\begin{array}{l}\text { Huérfano, carencia de socialización, abandonado por los padres, } \\
\text { agresión física, embarazo temprano de las madres, hurto. }\end{array}$ \\
\hline Orientadora & $\begin{array}{l}\text { Falta de supervisión por adultos, acoso y agresión entre pares, } \\
\text { maltrato físico en la familia, hacinamiento, }\end{array}$ \\
\hline Trabajadora & $\begin{array}{l}\text { Tráfico y consumo de sustancias ilegales en los familiares de los } \\
\text { niños, abuso de poder del docente hacia el estudiante, }\end{array}$ \\
\hline
\end{tabular}




\section{Entrevistas a Docentes de Educación Primaria}

Los docentes son quienes en la escuela pasan mayor tiempo con los jóvenes, resultado de este acercamiento es que de allí se deriva un mayor conocimiento de sus bondades, debilidades y fortalezas de sus condiciones familiares. En otras palabras, el convivir más tiempo con los estudiantes les da una visión muy amplia de sus personalidades. Si embargo, en este convivir docente-alumno también surgen manifestaciones de intolerancia, incomprensión, alejamientos, contadas veces admiración y muchos enfrentamientos. Ejemplo de ello fueron las expresiones de la maestra de primer grado, al preguntarle ¿Cómo haces para mantener la disciplina en el aula?

Bueno, en realidad busco estrategias como los juegos. En oportunidades tengo que el que se porte mal no va al recreo, mentiras piadosas para que ellos traten de... A cada ratico estoy, cállate, siéntate, vivo en tensión. En estos días tuve un problema con un niñito, siempre tenía que revisarle el bolso disimuladamente, porque al niñito siempre se le encontraban tres lápices, dos sacapuntas, cinco borradores, cosas así (009, 390-399).

El trabajo de aula es muy intenso, genera en los profesionales de la educación, en todos los niveles, un gran desgaste emocional y psicológico. Es común el lamento en cuanto a lo difícil que es impartir clases a los adolescentes de hoy, mantener la disciplina para cumplir con la planificación de clase. En este clima de insatisfacción es frecuente escuchar las quejas por la indisciplina escolar, la falta de apoyo de los padres o representantes, incluso de las mismas autoridades de la institución.

De allí que no es rara la expresión de la maestra de primer grado cuando dice que “...vivo en tensión (...) quien se porte mal no va al recreo”. Es decir, el estrés, la tensión nerviosa y emocional le hace tomar medidas contraproducentes, como privar al estudiante del momento de descanso y relajación, le castiga. Este hecho además de la frustración que puede causar en el niño, es un maltrato psicológico que no garantiza la corrección del comportamiento sancionado, al contrario si el niño es penado porque molesta en clase lo más seguro es que siga haciéndolo, ahora motivado por el cansancio y el aburrimiento.

Por otra parte, la docente de quinto grado es una profesional con 30 años en la docencia y goza de una jubilación por parte del sistema regional de educación, prestó servicios como maestra a una alcaldía perteneciente a la Zona Metropolitana de 
Caracas, de allí que el interés se centre en conocer parte de su experiencia laboral.

En este orden de ideas, la docente expresa "los muchachos son más groseros, hay problemas de violencia que antes no había” ¿A qué crees tú que se debe todo esto?

Yo creo que es a la TV, porque yo creo que anteriormente nosotros no veíamos tanto TV y los padres estaban pendientes de uno, entonces como no había TV, uno tenía que hacer la tarea, o que nosotros éramos más responsables o que los padres de nosotros nos ayudaban más”. Ahora los muchachos tienen esa agresividad. Los medios ahora todo el tiempo lo que transmiten es agresividad, pienso yo. (29, 1248-1256; 270-272).

La creencia de la docente, es intuitiva, no tiene evidencias del impacto de la televisión en el comportamiento de las personas. No obstante, existen estudios que afirman la influencia de los medios de comunicación en la conducta agresiva de algunos sujetos de la audiencia. Tal es el caso de Donnerstein (2004) quien sostiene que “...existen pruebas contundentes que confirman la relación entre la exposición a la violencia mediática y el comportamiento agresivo de los espectadores. Esta es la conclusión a la que se ha llegado tras cuarenta años de investigación sobre el tema por parte de las ciencias sociales" (p. 166).

Los medios masivos de comunicación representan factores importantes en la generación de la violencia, sobre todo aquellos manejados por consorcios internacionales en los que la comercialización de la violencia por televisión y otros medios producen abundantes recursos económicos, dichas empresas parecieran haberse deshumanizado. Los valores transmitidos son diferentes a lo que se enseñan y aprenden en el hogar, la escuela y la iglesia.

Otro factor importante es el entorno donde crecen y se desarrollan los estudiantes, éste marca de manera negativa su inserción social a la escuela, tal como lo describió la maestra de cuarto grado, quien al preguntarle sobre su experiencia en el aula expresó:

Tuve... por cierto, lo tengo allí, un exacto (especie de cuchilla), con José 9, me acuerdo clarito, José 5, trajo el exacto porque él le iba a dar por la cara a otro niño. Se lo llevaron, la mamá estaba presa por drogas y lo tenía una tía que no podía con él, total, ese muchachito era un desastre. Me dijeron que lo vieron aquí en Agua Salud pidiendo rial (dinero) y asaltaba en el centro comercial Propatria. El muchachito es un delincuente en potencia. José 5, debe tener ahorita como 9 o 10 años $(30,1290-1300)$. 
En los primeros años de vida del niño o niña la presencia, el contacto, el amor materno, el acercamiento que estimula los sentidos de la criatura es un todo que lo prepara en su desarrollo biopsicosocial, le brina seguridad en su inicio a la interacción social. Es de pensar entonces que el comportamiento agresivo debió ser consecuencia de su realidad cercana, donde las diferencias se solucionan con agresividad. Estar presa por drogas, implica que traficaba o vendía estas sustancias; a partir de estas circunstancias el niño no fue tratado convenientemente en el hogar ni en la escuela, estigmatizado por la conducta materna. Estos escenarios colocan al estudiante ante un alto riesgo social.

Cuadro 2.

Entrevistas a docentes de educación primaria

\begin{tabular}{l|l}
\hline \multicolumn{1}{c|}{ DOCENTE } & \multicolumn{1}{c}{ SITUACIONES REPORTADAS } \\
\hline Primer grado & $\begin{array}{l}\text { Tensión nerviosa y emocional, estrés, privar a los estudiantes del } \\
\text { recreo }\end{array}$ \\
\hline Quinto grado & $\begin{array}{l}\text { Impacto de programas de televisión en el comportamiento de los } \\
\text { estudiantes. }\end{array}$ \\
\hline Cuarto grado & Contexto familiar agresivo, alto riesgo social \\
\hline
\end{tabular}

\section{Entrevistas a los Alumnos}

El alumno tiene unas condiciones hogareñas que no les facilitan un mayor bienestar e integración. Muestra de ello fueron las respuestas a las preguntas ¿Tienes otros hermanos? "Si, por parte de mi papá, una hembra y un varón” ¿Tu papá vive contigo? “No, yo vivo con mi mamá” ¿Ella trabaja? "Si” ¿Qué pasa con la guía de geografía? “Mi mamá me la comprará después” ¿Desayunaste? "No”. Lo invito a comer una empanada (003,90-95).

Los elementos que marcaron las respuestas es la estructuración del núcleo familiar, como en otros casos narrados anteriormente, es monoparental, solamente la madre es la proveedora de los recursos económicos para la manutención del hogar. Esto, por consiguiente genera una estrechez económica que impide al estudiante constituir todos los recursos necesarios exigidos por los docentes; sin mencionar otras carencias como la alimentación requerida en su etapa de desarrollo biológico. 
La carencia económica lleva consigo la connotación de pobreza, la falta de suficientes recursos para satisfacer las necesidades básicas del hogar. Esta privación es debida, en la mayoría de las veces, porque los proveedores naturales del grupo familiar están desempleados o la actividad laboral que desempeñan no genera suficientes recursos.

El uso del uniforme es otro factor que concita sanciones como impedir la permanencia en clases de los estudiantes. Al profesor retirarse, le pregunté al estudiante: ¿Por qué no trajiste el uniforme de Educación Física? "El uniforme está sucio” ¿Por qué no lo lavaron? "Se me olvidó” (003,117-119).

Los docentes deben establecer normas de disciplina y comportamiento en sus clases, pero el acto de excluir a un alumno por no cumplir con el porte del uniforme a la larga trae peores consecuencias: el alumno queda libre en la escuela sin ninguna actividad, este tiempo libre le puede llevar a cometer actos que comprometen la disciplina o a alterar el orden del establecimiento.

Esté (1999: 112), sostiene que “...el uniforme es el distintivo que convierte al estudiante miembro de la comunidad educativa..." En el caso que se describe, el docente pudiese haberle permitido al estudiante realizar algunas actividades que no implicaran el ingreso a la cancha deportiva. Debido a que "... las sanciones propinadas por el uso indebido del uniforme pueden generar rebeldía del estudiante contra la escuela" (ob. cit: 112).

En otro orden de ideas, no son pocas las ocasiones cuando se suscitan dentro del aula situaciones de hurtos de materiales escolares o pertenencias personales entre el grupo de alumnos. Es raro cuando los docentes que encaran estos incidentes toman medidas acertadas para resolverlos, debido en gran parte a su falta de formación en áreas específicas relacionadas con estos aspectos, proceden a improvisar sanciones, que por su carácter emergente mayormente no son asertivas. Tal fue el caso contado por el estudiante:

"El lapso pasado se perdió un celular y nos suspendieron varios días. Si los representantes no lo pagaban, no podíamos incorporarnos a clase. No estoy de acuerdo porque es apoyar la conducta del ladrón. Yo no sabía quién se lo robó, si no lo hubiera dicho" (005, 205-214). 
El hurto en el aula suele ser un comportamiento generalizado en el cual varía la frecuencia y el valor económico de los objetos sustraídos. Es de esperar que pasadas las primera y segunda etapas de educación básica este proceder se vea atenuado debido a la madurez psicoevolutiva y social de los alumnos. Sin embargo, como lo evidencia la narración del estudiante, esta conducta persiste en edades adolescentes (los alumnos cuando cursan noveno grado promedian los 14 ó 15 años de edad). Este tipo de situaciones, aún sin prestar atención a las motivaciones que impulsan a uno o más estudiantes a cometer tales hechos, los resultados son los mismos interrupción de las actividades diarias de la clase, el desasosiego, la incertidumbre, la sospecha y pérdida de tiempo por parte de toda la sección escolar.

Luego, las sanciones y amonestaciones a ciegas, ya que por lo general nunca se sabe quien cometió la irregularidad, todos pagan las consecuencias. La institución educativa en estos casos tiene el doble discurso de la honestidad, la solidaridad, los valores que deben prevalecer en el comportamiento ciudadano, etc. y por otra parte, asume actitudes reñidas con estos principios; establece condiciones difíciles de cumplir por el grupo de estudiantes, en vez de asumir la negociación y el diálogo, buscar otras salidas que garanticen la no repetición del hecho.

Un suceso registrado en la Unidad Educativa, en el cual tres jóvenes de $9^{\circ}$ grado B, todas de 14 años, fueron amonestadas por consumir alcohol en las adyacencias de la escuela en horas de clase y con consecuencias bochornosas, tanto para ellas como para sus representantes. Les pregunté si anteriormente habían ingerido bebidas alcohólicas, una de ellas contestó: "Sí algunas veces con mi madrastra, me pareció cool” (38, 1593-1594).

Es indudable la influencia de los responsables del hogar en el comportamiento de la escolar, en este caso el adulto está en contraposición con todos los principios legales que resguardan de estas condiciones a los menores. Los padres (o los responsables inmediatos) en el hogar desempeñan una función vital para orientar, impedir y vigilar los comportamientos de los menores referentes al uso del licor. Los padres o apoderados de los niños y jóvenes, deben servir como modelo de conducta en el uso del alcohol, controlar la disponibilidad de bebidas alcohólicas por parte de los jóvenes.

Otra de las jóvenes protagonista del suceso agregó "Me dio rabia porque me hicieron firmar el Libro de Vida y no a las otras muchachas que también habían tomado” (38, 
1598-1599). De esta respuesta se infirió que la mayor preocupación de la estudiante no es el bochorno ni la vergüenza de haber cometido una falta en la escuela, sino las medidas de castigo esgrimidas hacia ella.

Interpreto que el sentimiento y la consciencia de haber incurrido en un hecho pugnado con las costumbres y comportamientos propios de la escuela no le merecen mayor importancia, por tanto, es proclive de cometerlo nuevamente. La rabia expresada en la conversación es derivada de lo que considera una injusticia: “...me hicieron firmar el libro de vida y no a las otras...".

En resumen, la estudiante no reconoció su falta, alegando que no fue sancionada al igual que las otras compañeras, consideró que le obligaron a aceptar una sanción en la cual la única perjudicada fue ella. Se pone de manifiesto nuevamente que la escuela se encarga más del acto punitivo que una debida orientación dirigida a la adolescente.

La otra estudiante expresó "Bueno, he tomado alcohol en otras oportunidades, en reuniones familiares, pero en esta oportunidad me sentí muy mal. Hasta me llevaron a la jefatura, porque sospecharon que había otras drogas” (38,1601-1604). Se repitió la influencia cultural de muchos hogares venezolanos respecto al consumo alcohólico, como consecuencia de que este hábito se considera un comportamiento socialmente admitido, familiarmente no es condenado. Cuando los jóvenes llegan a educación básica (tercera etapa) ya han vivido su primera borrachera. Es muy alto el consumo de estos productos en el país, anualmente se venden 1.760 millones de litros de cerveza (Linares, 2006).

Cuadro 3.

Entrevistas a los alumnos de la escuela

\begin{tabular}{c|l}
\hline ALUMNO & \multicolumn{1}{c}{ CONCEPTOS } \\
\hline 1 & $\begin{array}{l}\text { Estructura disfuncional del núcleo familiar,, carencia económica, } \\
\text { exclusión }\end{array}$ \\
\hline 2 & Hurto, amonestaciones colectivas \\
\hline 3 & Consumo alcohólico \\
\hline
\end{tabular}




\section{Categorización de la Información}

Como resultado del análisis de las entrevistas a los miembros de la UPE, a los docentes de primera y segunda etapas, a algunos estudiantes, observaciones en el patio, canchas y otros espacios, se construyeron los protocolos, es decir, se sintetizaron los aspectos más resaltantes de la información recolectada; a partir de este resumen se realizó una nueva reducción de los datos, dando como resultado a lo que Martínez (2000) denomina áreas significativas o unidades temáticas.

Cuadro 4.

Unidades temáticas

\section{UNIDAD TEMÁTICA}

1. Adaptación social Adaptación al medio, dominado por el impacto de la privación, que al agudizarse produce un profundo desencanto y deterioro de las condiciones de vida. El sujeto aprecia como insalvables las diferencias entre las expectativas y los logros, dando así a un conjunto de situaciones como desesperanza, apatía y agresividad con el medio que le es inaccesible y que impone como respuesta reactiva distintas manifestaciones de violencia.

2.Desempeño Conjunto de conocimientos destrezas y actitudes aplicados en los
docente escenarios educativos. Muchas veces derivan en una red compleja de dominaciones sobre los padres, representantes y alumnos en la vida cotidiana que se desarrolla en la escuela, todo ello con el objetivo de lograr el control de la organización y defender sus intereses.

3.Estructura familiar La familia es considerada como un sistema complejo y abierto sometido a transformaciones continuas dentro del contexto de la comunidad. En el núcleo familiar predominan las relaciones conyugales inestables y prevalece una organización matricentrada o monoparental. En consecuencia, los niños mayores se hacen cargo del cuidado y supervisión de los menores, o algún familiar cercano o vecino asume la responsabilidad de los niños cuando la madre trabaja. Los infantes suelen quedarse solos en la casa o en la calle sin supervisión alguna o bajo la vigilancia de algún vecino.

\begin{tabular}{ll}
\hline 4. Riesgo social & Los problemas económicos, culturales, la desestructuración \\
& familiar, las conductas anómicas y otras circunstancias a escala \\
& comunitaria, familiar y personal que afectan a los ciudadanos. \\
& Son maneras de sentir, pensar y actuar que se expresan en los \\
& discursos y comportamientos de las personas en su contexto \\
& social particular.
\end{tabular}


En lo que respecta a la adaptación social, destaca la pobreza como macro indicador, el cual afecta la estructuración de los núcleos familiares, por lo general son núcleos monoparentales o totalmente desestructurados. A partir de estas condiciones se genera una cadena de carencias como condiciones críticas de salud a nivel de los niños y adolescentes; maltrato intrafamiliar, negligencia en la crianza de los niños, expresada en la falta de cuidado y vigilancia, de apoyo en el desarrollo cognitivo; se deriva también de tales condiciones, el uso de sustancias ilícitas, alto consumo de alcohol.

El problema que se plantea es que la escuela se convierte en una representación, a menor escala, del contexto donde está enclavada. Su cultura, entendida como las maneras de sentir, pensar, actuar que se expresan en los discursos, los valores y comportamientos de las personas que la conforman, no marcan diferencia a los que son propios de su ambiente social. Sin embargo, como organización la escuela tiene normas o principios que les son comunes con el entorno más amplio al que pertenece, así como disposiciones internas que les son propias, lo que hace de cada institución escolar un ente con un ethos particular.

Esta complejidad se expresa en las interacciones que se dan en el seno escolar. Un enfoque que permite dilucidar lo expresado en el párrafo precedente es el interaccionismo simbólico. Esta teoría sostiene que los seres humanos actúan en relación con los objetos del mundo físico y de otros seres de su ambiente, las premisas que la sustentan según Blumer (1969: 12) son:

(a)...la interpretación de los significados y los símbolos que cada quien le da a su realidad influye en las relaciones; (b) los significados se derivan de la interacción social que se da en el medio de los individuos. La comunicación es simbólica, ya que nos comunicamos por medio del lenguaje y otros símbolos, es más, al comunicarnos creamos o producimos símbolos significativos; (c) los significados se establecen y modifican por medio de un proceso interpretativo, el actor selecciona, modera, suspende, reagrupa y transforma los significados a la luz de la situación en que se encuentra y la dirección de su acción, es decir, los significados son usados y revisados como instrumentos para la guía y formación de la acción.

Entonces, se deduce con base en esta teoría que los símbolos y significados cuando son decodificados de la misma manera por quienes establecen la interacción, 
las relaciones son productivas, son escasas las situaciones de enfrentamientos y los conflictos se solucionan positivamente. Caso contrario, surgen las situaciones conflictivas, que en muchas oportunidades generan agresiones y maltratos.

En este orden de ideas, se asume que en la escuela interviene todo un sistema de jerarquías que conlleva un ejercicio de poder que incluye un vasto conjunto simbólico de significados. Este poder, asociado a la violencia contiene prácticas como el dominio, la disciplina y la coerción, pero también se expresa en prácticas como la negociación y los acuerdos entre partes no simétricas.

A partir de estas consideraciones se propone que la violencia escolar presente en la escuela seleccionada tiene los siguientes supuestos: (a) es invisible, la agresión proviene desde el sistema social, lo que hace difícil identificar al agresor; (b) es multifactorial, se conjugan diversos factores, propios de los sistemas desde donde se asuma su análisis (c) es ubicua, se encuentra difundida en todos los entornos: familiar, comunidad, escolar y relacional y (d) es socialmente reproducida, es decir, dadas las características socioeconómicas preponderantes en el país, es de suponer su aparición en contextos escolares similares.

En otras palabras, la violencia escolar, en esta investigación la denominamos violencia sistémica, la cual viene dada cuando las fuerzas que ejercen los sistemas político, económico y social afectan a las masas de ciudadanos en situación de vulnerabilidad. Las condiciones de vida de estos grupos sociales se ven afectadas en sus raíces, es decir, a partir del núcleo familiar.

Desde la perspectiva del pensamiento complejo, la violencia observada en este centro educativo es dialógica. La lógica sistémica que se impone con toda su fuerza y exigencias hacia los sujetos de la escuela, la propia lógica escolar y la de los sujetos que hacen vida en estas instituciones. Esta unidualidad compleja, según Ugas (2008), significa que dos términos son a la vez ineliminables e irreductibles, de igual manera, ninguno de los dos términos es reducible al otro, pero tampoco son nítidamente separables.

La recursividad en este contexto social se da desde los diferentes sistemas, es decir la violencia se da en los sujetos sociales y es producida en el seno de la sociedad, en otras palabras, se forma un bucle recursivo (Morin, 2008). Por su parte, el principio de autoeco-organización indica que en vez de aislar el objeto estudiado (la violencia en este 
caso) lo considere por su relación con su entorno (Ugas, 2008). En este caso particular, la violencia no puede ser estudiada de manera separada sino en su relación compleja con su entorno, es decir con su ecosistema social.

\section{REFLEXIONES FINALES}

De esta investigación se derivan ideas que contribuyen al discernimiento del comportamiento social de los miembros de una escuela venezolana. Asimismo, surgieron conocimientos empíricos producto de la evidencia suministrada por los actores escolares a partir de su cotidianidad que permitieron proponer una teoría de violencia escolar, cuyos orígenes se encuentran en los ámbitos social, familiar e institucional.

A partir de los resultados obtenidos, se da la oportunidad para comprender el fenómeno de violencia escolar; a su vez, la contrastación teórica de los hechos y la puesta en claro de los factores asociados a esta violencia fue una oportunidad propicia para formular una teoría de la violencia sistémica que contribuya a entender los fenómenos que subyacen en la convivencia de sus miembros.

Desde la perspectiva social, se logró entender las situaciones derivadas del acontecer humano en áreas restringidas como son las aulas, esta comprensión contribuirá a buscar opciones para disminuir las tensiones sociales que perturban la estabilidad emocional, psicológica y anímica de las individualidades que integran el grupo de una organización tan compleja como es la escuela; a la vez que contribuyan positivamente a la resolución de conflictos, allanen el camino para la convivencia pacífica, estimulen la amistad, la cooperación, la solidaridad, la aceptación del otro, como un ser que piensa y actúa diferente, además comparte día a día muchas más cosas que el hecho común de aprender.

Las condiciones de vida de la comunidad escolar están afectadas por el sistema socioeconómico que ocasiona un amplio cúmulo de restricciones y déficits, de vulnerabilidad social e indefensión. Esta situación determina consecuencias negativas dando origen a un conjunto de factores de riesgo que dificulta la adaptación social y desempeño de los niños y jóvenes en la escuela y un alto riesgo que afecta sus expectativas de inserción social y cultural. 
La escuela en estas circunstancias es una estructura ineficaz, esta incapacidad de acción viene dada por la pérdida de su pertinencia social. Es una organización que ignora, es ciega a los problemas sociales de la comunidad aledaña lo cual contribuye, en gran parte, a las frecuentes manifestaciones del comportamiento violento de sus miembros. Por otra parte, las carencias de servicios de salud dentro del recinto escolar obligan al personal responsable de los niños y adolescentes a remitirlos a otras instituciones. Pero, dadas las precarias condiciones que padecen estos núcleos familiares la mayoría de las veces no proceden a buscar ayuda, ocasionando una violencia social, que por omisión, crea un círculo dañino que compromete de manera negativa al desarrollo integral del estudiante

Los docentes ubican la problemática del comportamiento de sus alumnos, así como su desempeño en el aula, fuera de la escuela, en el hogar. La responsabilidad de moldear el comportamiento social y la adaptación a la cultura escolar es eludida. Los padres y representantes, por su parte atribuyen la responsabilidad a la escuela, de tal manera que se crea un vacío en la toma de decisiones respecto a situaciones que atañen a los jóvenes y que a la larga los perjudica.

Algunos procedimientos de profesores y maestros están dirigidos a la punición y la exclusión, tanto del aula como de la escuela. En función de ello, la formulación consensuada de normas para la convivencia pudiera ser un factor que contribuya a mejorar el clima de la organización.

Sumado a estas normas se propulsaría la formación permanente del docente, con el fin de incidir en un mejor desempeño en el aula, limitando el uso de materiales didácticos no adaptados a las realidades particulares de esta escuela; la racionalización y comprensión de las realidades sociales de los estudiantes y sus núcleos familiares, permitirían reenfocar los mecanismos de control y supervisión en la escuela, en donde predominen otras visiones que ayuden a prevenir el surgimiento de conflictos.

Para tal fin, se podrían diseñar, con un enfoque epistemológico basado en el pensamiento complejo, programas permanentes, talleres y otras actividades similares que agilicen la solución de estos problemas. Es imprescindible visualizar las condiciones socioeconómicas y ambientales para poder exigir a los estudiantes de manera cónsona a sus posibilidades. 


\section{REFERENCIAS}

Blumer, H. (1969). Symbolic interactionism: Perspective and method. Nueva Jesey: Prentice Hall.

Donnerstein, E. (2004). Medios de comunicación. En J. Sanmartín (Coord). El laberinto de la violencia: causas, tipos y efectos (pp.165-173). Barcelona, España: Ariel.

Esté, A. (1999). El aula punitiva. Descripción y característica de las actividades en el aula de clase. Caracas: Publicaciones UCAB. Tercera edición.

Ley Orgánica de Educación (LOE). (2009). Gaceta Oficial de la República Bolivariana de Venezuela. 5.929 (Extraordinario). Agosto 15, 2009.

Ley Orgánica para la Protección del Niño, Niña y del Adolescente (LOPNNA). (1998). Gaceta Oficialde la República Bolivariana de Venezuela.5.266 (Extraordinaria), Octubre 2, 1998.

Linares, Y. (2006, Agosto 13). Tomamos hasta que se nos acabe la plata: Año 2006 [Periódico]. El Nacional. Cuerpo B, 15.

Martínez, M. (2000). La investigación cualitativa etnográfica en educación: Manual teórico-práctico. México: Trillas.

Morin, E. (2008). Introducción al pensamiento complejo. Barcelona: Gedisa Editorial.

Pérez, G. (2000). Modelos de investigación cualitativa. Madrid: Narcea, S. A. De Ediciones.

Ross, J. (1999). Escuelas, complicidad y fuentes de la violencia. En J Ross, y A Watkinson (Dir.), La violencia en el sistema educativo. Del daño que las escuelas causan a los niños. 14-47. Madrid: La Muralla.

Ugas, G. (2008). La complejidad. Un modo de pensar. Táchira, Venezuela: Ediciones Taller Permanente de Estudios Epistemológicos en Ciencias Sociales. 